\title{
Rebeccamycin Attenuates TNF- $\alpha$-Induced Intestinal Epithelial Barrier Dysfunction by Inhibiting Myosin Light Chain Kinase Production
}

\author{
Akihiro Watari Yuta Sakamoto Kota Hisaie Kazuki Iwamoto Miho Fueta \\ Kiyohito Yagi Masuo Kondoh
}

Laboratories of Bio-Functional Molecular Chemistry, Graduate School of Pharmaceutical Sciences, Osaka University, Suita, Osaka, Japan

\section{Key Words}

Checkpoint kinase 1 - Epithelial barrier - Intestinal cells • Myosin light chain kinase - Tight junction $\cdot$ TNF- $\alpha$

\begin{abstract}
Background/Aims: Although proinflammatory cytokine-induced disruption of intestinal epithelial barrier integrity is associated with intestinal inflammatory disease, effective treatment for barrier dysfunction is lacking. Previously, we demonstrated that rebeccamycin alleviates epithelial barrier dysfunction induced by inflammatory cytokines in Caco-2 cell monolayers; however, the underlying mechanism remained unclear. Here, we investigated the mechanism by which rebeccamycin protects the epithelial barrier function of Caco-2 cells exposed to TNF- $\alpha$. Methods: To confirm the epithelial barrier function of Caco-2 cell monolayers, transepithelial electrical resistance (TER) and paracellular permeability were measured. Production levels and localization of tight junction (TJ) proteins were analyzed by immunoblot and immunofluorescence, respectively. Phosphorylated myosin light chain (pMLC) and MLC kinase (MLCK) mRNA expression levels were determined by immunoblot and quantitative RT-PCR, respectively. Results: Rebeccamycin attenuated the TNF- $\alpha$-induced reduction in TER and increase in paracellular permeability. Rebeccamycin increased claudin- 5 expression, but not claudin-1, $-2,-4$, occludin or ZO-1 expression, and prevented the TNF- $\alpha$-induced changes in ZO-1 and occludin localization. Rebeccamycin suppressed the TNF- $\alpha$-induced increase in MLCK mRNA expression, thus suppressing MLC phosphorylation. The rebeccamycin-mediated reduction in MLCK production and protection of epithelial barrier function were alleviated by Chk1 inhibition. Conclusion: Rebeccamycin attenuates TNF- $\alpha$-induced disruption of intestinal epithelial barrier integrity by inducing claudin- 5 expression and suppressing MLCK production via Chk1 activation.
\end{abstract}




\section{Cellular Physiology $\quad$ Cell Physiol Biochem 2017;41:1924-1934 \\ \begin{tabular}{l|l} 
and Biochemistry Published onIIne: AprIIO7, 2017 & $\begin{array}{l}\text { (c) 2017 The Author(s). Published by S. Karger AG, Basel } \\
\text { www.karger.com/cpb }\end{array}$ \\
\hline
\end{tabular} \\ Watari et al.: Rebeccamycin Attenuates TNF- $\alpha$-Induced TJ Barrier Dysfunction}

\section{Introduction}

The intestinal epithelium is composed of a single-cell layer and forms a selectively permeable barrier that allows the entry of dietary nutrients, electrolytes, and water, while preventing foreign antigens, toxins, and microorganisms from penetrating the intestinal lumen and accessing the systemic circulation [1-6]. Disruption of the barrier functions of the intestinal epithelium increases the epithelium's permeability to noxious intestinal contents and contributes to the development of intestinal inflammation; barrier defects have been associated with several intestinal diseases, including inflammatory bowel disease (IBD), celiac disease, and irritable bowel syndrome (IBS) [3, 7].

The barrier function of the intestinal epithelium is maintained partly by tight junctions (TJs) present in the spaces between adjacent epithelial cells. TJs are the apicalmost junctional complexes and appear as a complex network of intramembranous particle strands (TJ strands) on freeze-fracture electron microscopy [8]. TJs are composed of membrane proteins such as occludin, the claudins, and junctional adhesion molecule (JAM), as well as cytoplasmic scaffolding proteins such as zonula occludens- $1,-2,-3$ (ZO-1, -2, $-3)$, and cingulin $[9,10]$. The intestinal barrier function in IBD patients is compromised by decreases or increases in the production levels of several TJ proteins or by changes in their distribution. In patients with Crohn's disease (CD) or ulcerative colitis (UC), the number of TJ strands is decreased and strand breaks appear; in addition, the levels of production of TJ proteins (claudin-3, $-2,-5,-8$, and occludin) are changed in the intestinal tissues [11]. These alterations result in impairment of the intestinal barrier, leading to increased intestinal permeability and infiltration of pathogens.

Several proinflammatory cytokines, including tumor necrosis factor (TNF)- $\alpha$, interferon (IFN)- $\gamma$, and interleukin (IL)-1b, IL-6, and IL-13, are associated with the pathology of IBD [12-15]. TNF- $\alpha$ is a crucial factor in the intestinal inflammation of CD and other inflammatory disorders [16]. Numerous clinical studies have found that TNF- $\alpha$ levels are significantly increased in the intestinal tissues of CD patients [17-19], and anti-TNF- $\alpha$ antibody therapy is used widely to treat CD and UC patients $[16,19,20]$. Likewise, anti-TNF- $\alpha$ antibody is effective in animal models of intestinal inflammation [21]. TNF- $\alpha$ contributes to an increase in intestinal epithelial TJ permeability $[22,23]$ and directly activates immunoregulatory pathways. Moreover, anti-TNF- $\alpha$ therapy in CD patients substantially restores intestinal barrier function, indicating that dysfunction of the intestinal barrier in IBD patients is caused at least partly by the action of TNF- $\alpha$. Although the mechanism underlying the effect of TNF- $\alpha$ on TJ permeability has not been clearly defined, several reports have revealed that myosin light chain (MLC) kinase (MLCK), an essential regulator of actomyosin function that shows increased production in the intestinal tissue of IBD patients, is a critical factor in TNF$\alpha$-induced intestinal barrier disruption [24]. TNF- $\alpha$ treatment induces MLCK production in intestinal epithelial cells, which leads to an increase in MLC phosphorylation and subsequent disruption of the TJ barrier [25]. Similarly, administration of an MLCK inhibitor suppresses TNF- $\alpha$-induced intestinal permeability [26], although this effect on barrier function appears to be cell-line dependent [27]. These findings suggest that MLCK is essential for the increase in intestinal permeability induced by TNF- $\alpha$.

In a previous study, we showed that rebeccamycin, a DNA-damaging agent that acts by inhibiting topoisomerase I [28], enhanced TJ barrier function in intestinal cells. Furthermore, rebeccamycin ameliorated the epithelial barrier dysfunction triggered by TNF- $\alpha$ and IFN- $\gamma$ [29]. However, the detailed mechanism underlying the protective effect of rebeccamycin on proinflammatory cytokine-induced intestinal barrier dysfunction remains unclear. Therefore, here, we investigated the mechanistic basis for the protective effect of rebeccamycin on TNF- $\alpha$-induced barrier dysfunction in Caco- 2 cell monolayers. 


\section{Cellular Physiology Cell Physiol Biochem 2017;41:1924-1934 \begin{tabular}{ll|l} 
and Biochemistry Published onlIne: Aprilu7, 2017 & $\begin{array}{l}\text { C } 2017 \text { The Author(s). Published by S. Karger AG, Basel } \\
\text { www.karger.com/cpb }\end{array}$
\end{tabular} \\ Watari et al.: Rebeccamycin Attenuates TNF- $\alpha$-Induced TJ Barrier Dysfunction}

\section{Materials and Methods}

\section{Cell culture}

The human colorectal adenocarcinoma cell line Caco-2 (HTB-37) was obtained from the American Type Culture Collection (Rockville, MD, USA). Caco-2 cells were cultured in Eagle's minimum essential medium (Nissui, Japan) supplemented with $10 \%$ FBS under $5 \% \mathrm{CO}_{2}$ at $37{ }^{\circ} \mathrm{C}$. The number of passages used for the experiments was between 15 and 25.

\section{Reagents and antibodies}

Rebeccamycin was purchased from Sigma-Aldrich (St. Louis, MO, USA). SB-218078, a selective inhibitor of checkpoint kinase (Chk1), was purchased from Calbiochem (San Diego, CA, USA). Recombinant human TNF- $\alpha\left(7.6 \times 10^{4} \mathrm{IU} / \mu \mathrm{g}\right)$ was purchased from R\&D Systems (Minneapolis, MN, USA). Rabbit anticlaudin-1 polyclonal antibody (pAb), mouse anti-claudin-4 monoclonal Ab (mAb), mouse anti-occludin $\mathrm{mAb}$, and rabbit anti-ZO-1 pAb were purchased from Invitrogen (Carlsbad, CA, USA). Rabbit anti-myosin light chain $2 \mathrm{pAb}$ and mouse anti-phospho-myosin light chain $2 \mathrm{mAb}$ were purchased from Cell Signaling Technology (Beverly, MA, USA). Mouse anti- $\beta$-actin mAb was purchased from Sigma-Aldrich. Goat antirabbit IgG peroxidase-conjugated antibody and goat anti-mouse IgG peroxidase-conjugated antibody were purchased from Millipore (Bedford, MA, USA). Alexa Fluor 488 goat anti-rabbit IgG and Alexa Fluor 594 phalloidin were purchased from Molecular Probes (Eugene, OR, USA).

\section{Measurement of intestinal barrier function}

Epithelial barrier function was assessed by measuring transepithelial electrical resistance (TER) and the flux of 4-kDa fluorescein isothiocyanate (FITC)-labeled dextran in human intestinal Caco-2 cell monolayers. In the TER assay, Caco- 2 cells were seeded into Transwell chambers (diameter, $6.5 \mathrm{~mm}$; pore size, $0.4 \mu \mathrm{m}$; Corning, MA, USA) at a density of $6 \times 10^{4}$ cells/well and cultured for 10 to 14 days. After the TER values had plateaued (500 to $700 \Omega \bullet \mathrm{cm}^{2}$ ), TNF- $\alpha$ was added to the basolateral side in the absence or presence of rebeccamycin, which was applied to the apical and basolateral sides, and TER was measured with a Millicell-ERS epithelial volt-ohmmeter (Millipore Corporation, Billerica, MA, USA).

In the paracellular tracer flux assay, Caco-2 cells were cultured in Transwell chambers (diameter, $6.5 \mathrm{~mm}$; pore size, $0.4 \mu \mathrm{m}$; Corning, MA, USA) for 10 to 14 days at a density of $6 \times 10^{4}$ cells/well. After equilibration of the culture with P buffer (10 mM HEPES [pH 7.4], $1 \mathrm{mM}$ sodium pyruvate, $10 \mathrm{mM}$ glucose, $3 \mathrm{mM} \mathrm{CaCl}_{2}$, and $145 \mathrm{mM} \mathrm{NaCl}$ ), $100 \mu \mathrm{M}$ dialyzed 4-kDa FITC-labeled dextran (Sigma-Aldrich, St. Louis, MO, USA) in P buffer was added to the upper chamber. After incubation of the sample for $1 \mathrm{~h}$, the concentration of 4-kDa FITC-dextran in the lower chamber was determined by measuring the fluorescence with a TriStar LB 941 microplate reader (Berthold Technologies, Wildbad, Germany).

Quantitative reverse transcription - PCR ( $q R T$-PCR) analysis

MLCK mRNA levels were analyzed by means of qRT-PCR analysis. After treatment with reagents, Caco-2 cells were washed with PBS and total RNA was extracted with Sepasol-RNA I Super G (Nakalai Tesque, Kyoto, Japan). Total RNA ( $3 \mu \mathrm{g}$ ) was reverse transcribed to cDNA with a cDNA synthesis kit (Roche, Mannheim, Germany) in accordance with the manufacturer's instructions. The resulting cDNA was used for qRT-PCR analysis. qRT-PCR was performed with SYBR Premix Ex Taq II (Takara, Shiga, Japan) and an Applied Biosystems StepOne Plus system (Applied Biosystems, Foster City, CA). Relative quantification was performed against a standard curve, and the values were normalized to those for the housekeeping gene glyceraldehyde 3-phosphate dehydrogenase (GAPDH). PCR primers were as follows: MLCK, (forward) 5' - GAGGTGCTTCAGAATGAGGACG-3' and (reverse) 5' - GCATCAGTGACACCTGGCAACT-3'; GAPDH, (forward) 5'-GGTGGTCTCCTCTGACTTCAACA-3' and (reverse) 5'-GTGGTCGTTGAGGGCAATG-3'.

Preparation of cell lysates and immunoblot analysis

Caco- 2 cells were seeded into Transwell chambers (diameter, $24 \mathrm{~mm}$; pore size, $0.4 \mu \mathrm{m}$; Corning) at a density of $7.5 \times 10^{5}$ cells/well and cultured for 10 to 14 days. Cells were lyzed with cell lysis buffer (10 $\mathrm{mM}$ Tris-HCl [pH 7.4], 0.3\% SDS) containing protease inhibitor cocktail (Sigma-Aldrich) and phosphatase inhibitor cocktail (Nakalai). Cell lysates were centrifuged at $15,600 \times g$ for $20 \mathrm{~min}$ at $4{ }^{\circ} \mathrm{C}$. The supernatant of the cell lysates was run on an SDS-polyacrylamide gel and electroblotted onto a polyvinylidene difluoride (PVDF) membrane. The membranes were incubated successively with antibodies against claudin-1 and -4 , occludin, ZO-1, MLC2, phospho-MLC2, or $\beta$-actin, and then with a horseradish peroxidase-conjugated anti- 


\section{Cellular Physiology Cell Physiol Biochem 2017;41:1924-1934 \\ \begin{tabular}{ll|l} 
DOI: 10.1159/000472367 & $\begin{array}{l}\text { O 2017 The Author(s). Published by S. Karger AG, Basel } \\
\text { wwww.karger.com/cpb }\end{array}$
\end{tabular} \\ Watari et al.: Rebeccamycin Attenuates TNF- $\alpha$-Induced TJ Barrier Dysfunction}

rabbit or -mouse IgG antibody. Reactive bands were detected with Chemi-Lumi One (Nakalai), and signals were visualized with an ImageQuant LAS4010 imaging system (GE Healthcare).

\section{Immunofluorescence analysis}

Caco- 2 cells were seeded in Transwell chambers (diameter, $12 \mathrm{~mm}$; pore size, $0.4 \mu \mathrm{m}$; Corning) at a density of $1.5 \times 10^{5}$ cells/well and cultured for 10 to 14 days. After treatment with TNF- $\alpha(10 \mathrm{ng} / \mathrm{mL})$ or rebeccamycin $(1 \mu \mathrm{M})$ or both, Caco-2 cells were fixed with $4 \%$ paraformaldehyde for $15 \mathrm{~min}$ and then permeabilized with $0.2 \%$ Triton X-100 in PBS for $5 \mathrm{~min}$. Cells were then blocked for $1 \mathrm{~h}$ with $1 \%$ BSA in TBS buffer (20 mM Tris-HCl [pH 7.4], $40 \mathrm{mM} \mathrm{NaCl)} \mathrm{containing} \mathrm{0.05 \%} \mathrm{Tween-20} \mathrm{(T-TBS)} \mathrm{and} \mathrm{incubated}$ with anti-occludin or ZO-1 antibody in 1\% BSA in T-TBS overnight; this was followed by an incubation with secondary fluorescence antibodies for $1 \mathrm{~h}$. For F-actin staining, cells were incubated with $0.33 \mu \mathrm{M}$ Alexa Fluor 594 phalloidin for $1 \mathrm{~h}$. Immunofluorescence images were captured under a fluorescence microscope (Keyence, Tokyo, Japan).

\section{Statistical analysis}

Data are presented as means \pm SD. Dunnett's or Tukey's test was used for statistical analyses. A $P$ value of less than 0.05 was considered indicative of statistical significance.

\section{Results}

Rebeccamycin attenuates epithelial barrier dysfunction induced by TNF- $\alpha$

To investigate the effect of rebeccamycin on TNF- $\alpha$-mediated disruption of intestinal epithelial barrier function, we treated Caco- 2 cell monolayers with $10 \mathrm{ng} / \mathrm{mL}$ TNF- $\alpha$ and 1 $\mu \mathrm{M}$ rebeccamycin and then measured transepithelial electrical resistance (TER) as an index of epithelial barrier function. TNF- $\alpha$-induced reduction in the TER level was significantly suppressed by co-administration of rebeccamycin (Fig. 1A). Furthermore, treatment with rebeccamycin restored the TNF- $\alpha$-induced reduction in the TER level earlier than did treatment with vehicle (Fig. 1B). We next examined the effect of rebeccamycin on the paracellular tracer permeability of Caco- 2 cell monolayers treated with TNF- $\alpha$. Consistent with the results of the TER analysis, TNF- $\alpha$ increased the paracellular flux of 4-kDa FITCdextran, as a paracellular tracer, in Caco-2 cell monolayers (Fig. 1C), and this increased paracellular flux was significantly suppressed by co-treatment with rebeccamycin. The cytotoxicity of TNF- $\alpha$ was assessed by using an LDH release assay (Fig. 1D) and detecting cleaved PARP (Fig. 1E). TNF- $\alpha$ was not cytotoxic to Caco-2 cells. These results indicated that rebeccamycin ameliorated the TNF- $\alpha$-induced disruption of the epithelial barrier function of Caco- 2 cell monolayers.

\section{Rebeccamycin inhibits the TNF- $\alpha$-induced change in localization of tight junction components \\ Epithelial tight junction (TJ) barrier function is regulated by various TJ components.} To investigate the effect of rebeccamycin on TJ components treated with TNF- $\alpha$, or left untreated, we performed a Western blotting analysis. Total production levels of the TJ proteins claudin- $1,-2,-4$, and -5 , occludin, and ZO- 1 were not altered by TNF- $\alpha$ treatment (Fig. 2A and B). Previous studies have also shown that TNF- $\alpha$ treatment has no effect on TJ proteins in Caco- 2 cells [30, 31]. In cells treated with both TNF- $\alpha$ and rebeccamycin, rebeccamycin increased claudin-5 expression, but it had no obvious effect on the production of claudin-1, -2 , or -4 , occludin, or ZO-1 (Fig. $2 \mathrm{~A}$ and $\mathrm{B}$ ), suggesting that rebeccamycin-induced induction of claudin- 5 expression attenuates the dysfunction of TJ barrier integrity provoked by TNF- $\alpha$.

The localization of TJ components is also critically important to barrier function. Previous studies have shown that TNF- $\alpha$ disrupts the localization of TJ components and leads to a decrease in barrier function in Caco- 2 cells $[30,31]$. We also confirmed that TNF- $\alpha$ treatment induced a change in the distribution of ZO-1 and occludin in Caco-2 cells. Vehicle-treated Caco-2 monolayers showed ZO-1 distribution at the membrane and occludin distribution 
Fig. 1. Rebeccamycin attenuates TNF- $\alpha$-induced disruption of tight junction barrier function in Caco-2 cell monolayers. (A) Caco-2 cell monolayers were treated with vehicle or TNF- $\alpha(10 \mathrm{ng} / \mathrm{mL})$ in the absence or presence of rebeccamycin $(1 \mu \mathrm{M})$. Transepithelial electrical resistance (TER) was measured every $24 \mathrm{~h}$. TER is presented as a percentage of the TER value at 0 h. $P<0.05$ vs. TNF- $\alpha$ treatment for 24 h $\left(^{*}\right)$ or 48 h (\#), as determined by Tukey's test. (B) Caco- 2 cells were incubated with vehicle or TNF- $\alpha$ (10 ng/mL). After a 48-h incubation, the medium was replaced with fresh medium that contained or lacked rebeccamycin $(1 \mu \mathrm{M})$, and the cells were cultured for an additional $24 \mathrm{~h}$. TER was measured every 24 h. $* P<0.05$ vs. TNF- $\alpha$ treatment $+24 \mathrm{~h}$, as determined by Tukey's test. (C) Caco- 2 cells were incubated with vehicle or TNF- $\alpha(10 \mathrm{ng} / \mathrm{mL})$ in the absence or presence of rebeccamycin $(1 \mu \mathrm{M})$. After a 48-h incubation, the flux of 4-kDa FITC-dextran was measured. Data are presented as means \pm SD $(n=3)$. $* P<0.05$ vs. TNF- $\alpha$ treatment, as determined by Tukey's test. (D) Caco-2 cell monolayers were treated with vehicle or TNF- $\alpha(10 \mathrm{ng} / \mathrm{mL})$ in the absence or presence of rebeccamycin $(1 \mu \mathrm{M})$ for 24 and $48 \mathrm{~h}$, after which LDH release was measured; $0.2 \%$ Tween 20 served as a positive control. LDH release was calculated as a percentage of the LDH release by the vehicle-treated cells. Data are presented as means \pm SD $(n=3)$. (E) Caco- 2 cell monolayers were treated for 24 and $48 \mathrm{~h}$ with vehicle or TNF- $\alpha(10 \mathrm{ng} / \mathrm{mL})$ in the absence or presence of rebeccamycin $(1 \mu \mathrm{M})$. The cell lysates were collected and immunoblotted for PARP. $\mathrm{H}_{2} \mathrm{O}_{2}$ served as a positive control.

in a characteristic chicken-wire staining pattern. In contrast, treatment with TNF- $\alpha$ disrupted the normal ZO-1 and occludin patterns, and some part hardly continuous (Fig. 3A and B). However, co-treatment with rebeccamycin and TNF- $\alpha$ prevented the TNF$\alpha$-induced alteration in the distributions of ZO-1 and occludin (Fig. 3A and B), suggesting that rebeccamycin prevents TNF- $\alpha$-induced alteration of the localization patterns of TJ proteins.

Rebeccamycin inhibits the TNF- $\alpha$-mediated increase in MLC phosphorylation via a reduction in MLCK production

It is well recognized that the MLCK-mediated phosphorylation of MLC elicited by proinflammatory cytokines plays a pivotal role in the physiological and pathophysiolo-

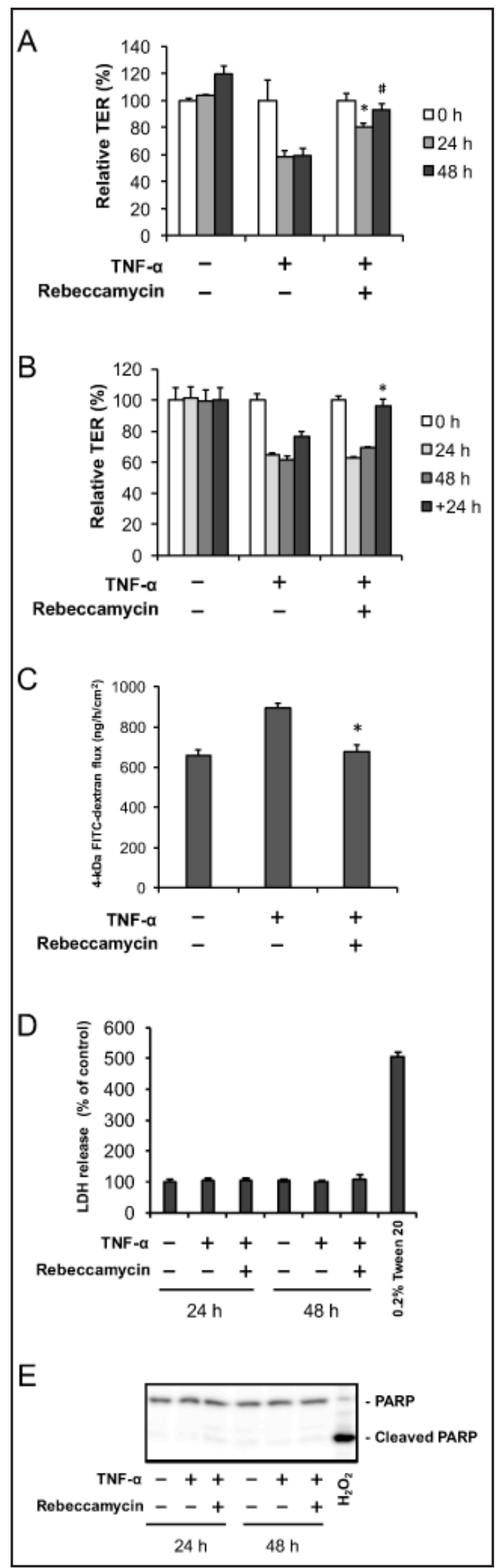


Fig. 2. Effects of TNF- $\alpha$ and rebeccamycin on production of tight junction proteins. Caco-2 cell monolayers were treated for $24 \mathrm{~h}$ with vehicle or TNF- $\alpha$ $(10 \mathrm{ng} / \mathrm{mL})$ in the absence or presence of rebeccamycin $(1 \mu \mathrm{M})$. The cell lysates were collected and immunoblotted for claudin (CLDN)-1, -2, -4, -5, occludin (OCLN), and ZO-1 (A). $\beta$-actin served as the loading control. Relative protein density was calculated as the ratio of the protein density to the density of the vehicle (B). Data are presented as means \pm SD $(\mathrm{n}=3)$.

gical regulation of intestinal epithelial barrier function and paracellular leak pathways [24]. Given the protective effect of rebeccamycin on intestinal epithelial barrier function, we examined the effect of rebeccamycin on MLC phosphorylation in Caco-2 cells treated with TNF- $\alpha$. Treatment of Caco-2 cells with TNF- $\alpha$ induced a significant increase in MLC phosphorylation without markedly changing the total MLC production level (Fig. $4 \mathrm{~A}$ and $\mathrm{B}$ ). In contrast, rebeccamycin treatment significantly attenuated the increase in MLC phosphorylation elicited by TNF- $\alpha$ in Caco- 2 cells. MLC phosphorylation influences F-actin organization, and TNF- $\alpha$ treatment has been shown to change the F-actin arrangement in Caco- 2 cells [32]. We, too, observed that TNF- $\alpha$ disrupted the assembly of F-actin, which normally stains intercellular sites along the edge of the cell (Fig. 4C and D). Similar to MLC phosphorylation, the TNF$\alpha$-induced disassembly of F-actin was attenuated by rebeccamycin treatment.

To examine the effect of rebeccamycin on MLCK, we evaluated MLCK production after TNF- $\alpha$ treatment. Rebeccamycin significantly decreased MLCK mRNA expression in a dosedependent manner (Fig. 5A). Furthermore, rebeccamycin significantly suppressed TNF- $\alpha$-induced MLCK mRNA expression (Fig. 5B). Taken together, these findings suggested that rebeccamycin suppressed MLC phosphorylation by inhibiting MLCK production.

Rebeccamycin-induced restoration of TNF- $\alpha$-mediated disruption of the barrier function depends on Chk1 activation

Our previous report showed that rebeccamycin-induced Chk1 activation
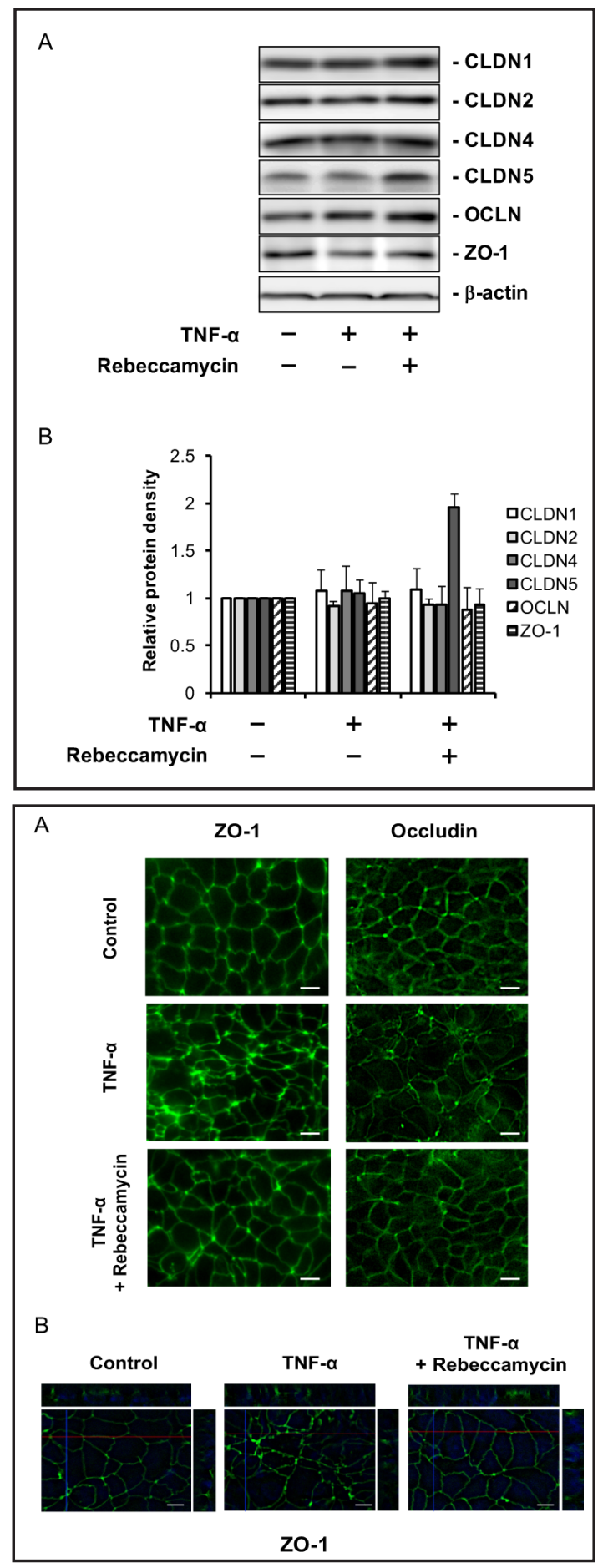

Fig. 3. Rebeccamycin prevents TNF- $\alpha$-induced morphological disruption of tight junctions. (A) Caco-2 cell monolayers were treated with vehicle or TNF- $\alpha$ $(10 \mathrm{ng} / \mathrm{mL})$ in the absence or presence of rebeccamycin $(1 \mu \mathrm{M})$ for $24 \mathrm{~h}$ and were then fixed and stained with anti-ZO-1 and occludin antibodies. (B) Z-stack analysis of representative images of ZO-1 staining. Z0-1, green; DAPI, blue. Images were collected under a fluorescence microscope. Scale bar $=10 \mu \mathrm{m}$. 
A

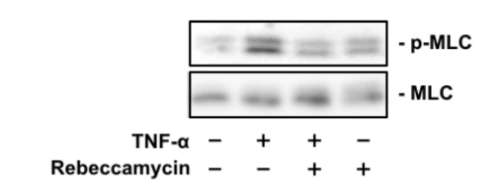

C

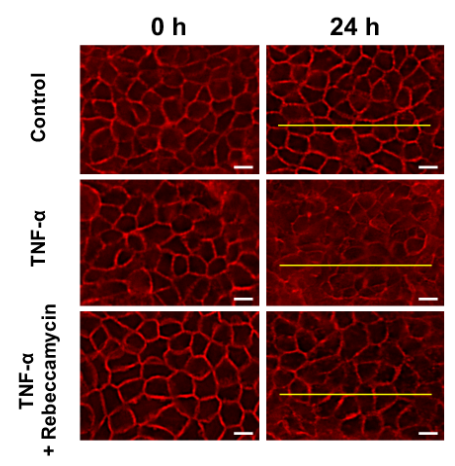

B

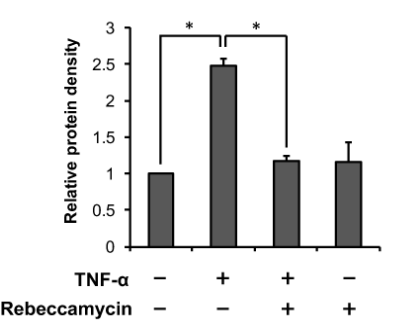

D
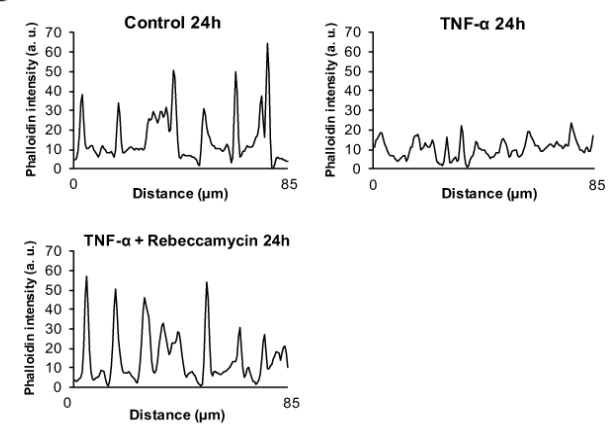

Fig. 4. Rebeccamycin suppresses the TNF- $\alpha$-induced increase in MLC phosphorylation. (A) Caco-2 cell monolayers were treated for $24 \mathrm{~h}$ with vehicle or TNF- $\alpha(10 \mathrm{ng} / \mathrm{mL})$ in the absence or presence of rebeccamycin $(1 \mu \mathrm{M})$. The cell lysates were collected and immunoblotted for MLC and p-MLC. Relative protein density of p-MLC was calculated as the ratio of the protein density to the density of the vehicle (B). ${ }^{*} P<0.05$, as determined by Tukey's test. (C) Cell monolayers were treated for $24 \mathrm{~h}$ with vehicle or TNF- $\alpha(10 \mathrm{ng} / \mathrm{mL})$ in the absence or presence of rebeccamycin $(1 \mu \mathrm{M})$, and were then fixed and stained with F-actin by using FITC-conjugated phalloidin. Images were collected under a fluorescence microscope. Scale bar $=10 \mu \mathrm{m}$. (D) Intensity profile scans of phalloidin staining along the indicated yellow lines. The intensity of phalloidin staining was measured by using the ImageJ program.

Fig. 5. Rebeccamycin suppresses the TNF- $\alpha$-induced increase in MLCK mRNA levels. (A) Caco-2 cell monolayers were treated for $24 \mathrm{~h}$ with vehicle or 0.1 , 0.5 , or $1 \mu \mathrm{M}$ rebeccamycin. Cell lysates were collected and subjected to qRT-PCR analysis for MLCK expression. ${ }^{*} P<0.05$ vs. vehicle-treated group, as determined by Dunnett's test. (B) Caco-2 cell monolayers were treated for $2 \mathrm{~h}$ with vehicle or TNF- $\alpha$ (10 $\mathrm{ng} / \mathrm{mL}$ ) in the absence or presence of rebeccamycin $(1 \mu \mathrm{M})$. Cell lysates were collected and subjected to qRT-PCR analysis for MLCK mRNA expression. Data are presented as means $\pm \mathrm{SD}(\mathrm{n}=3) .{ }^{*} P<0.05$, as determined by Tukey's test.

is essential for enhancement of barrier function in the Caco-2 cell monolayer [29]. Therefore, we investigated whether Chk1 activation was involved in the rebeccamycinmediated suppression of MLCK production. Rebeccamycin-induced reduction of MLCK mRNA expression was attenuated by the
A

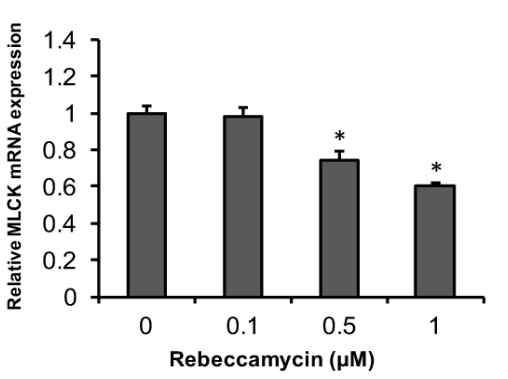

B

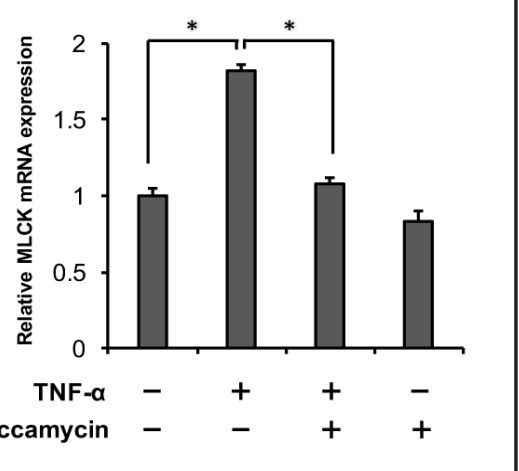


Chk1 inhibitor SB-218078 (Fig. 6A). Next, we examined the effect of SB-218078 on the rebeccamycin-induced restoration of barrier function. Restoration of the barrier function by rebeccamycin was significantly impaired by the Chk1 inhibitor (Fig. 6B). In contrast, the Chk1 inhibitor did not affect the TNF$\alpha$-induced reduction in barrier function. These results suggest that rebeccamycininduced restoration of the barrier function is dependent on Chk1 activity.

\section{Discussion}

We showed here that rebeccamycin ameliorates TNF- $\alpha$-induced dysfunction of intestinal epithelial barrier function in Caco2 cell monolayers. Specifically, rebeccamycin attenuates TNF- $\alpha$-induced TER reduction and the increase in paracellular permeability of FD-4. In our recent study, we demonstrated that rebeccamycin enhanced $\mathrm{TJ}$ barrier function via upregulation of claudin-5, which strengthens the TJ barrier function of epithelial and endothelial cells, in Caco2 cell monolayers [29]. These observations indicate that rebeccamycin has the potential to protect the epithelial barrier function against proinflammatory cytokine-mediated barrier dysfunction.

TNF- $\alpha$-induced barrier dysfunction of intestinal cells can be attributed to several factors, including apoptosis, and changes in the expression or localization (or both) of TJ components such as claudin-1, claudin-2, occludin, and ZO-1 [27, 30, 31, 33-35]. In this study, immunofluorescence analysis of TJ proteins showed that TNF- $\alpha$ altered the localization of occludin and ZO-1 in Caco-2 cells monolayers, whereas the levels of $\mathrm{TJ}$ protein components such as claudin-1, -2, and -4 , occludin, and ZO-1 did not change. Rebeccamycin suppressed the TNF- $\alpha$ induced change in the localization of $\mathrm{TJ}$ components, suggesting that rebeccamycin prevented TNF- $\alpha$-mediated TJ barrier dysfunction by normalizing the distribution of the affected TJ components. The TNF$\alpha$-induced alteration of the localization of the TJ components is associated with MLC phosphorylation, which can induce F-actin rearrangement $[32,36]$. MLC phosphorylation is thought to be associated

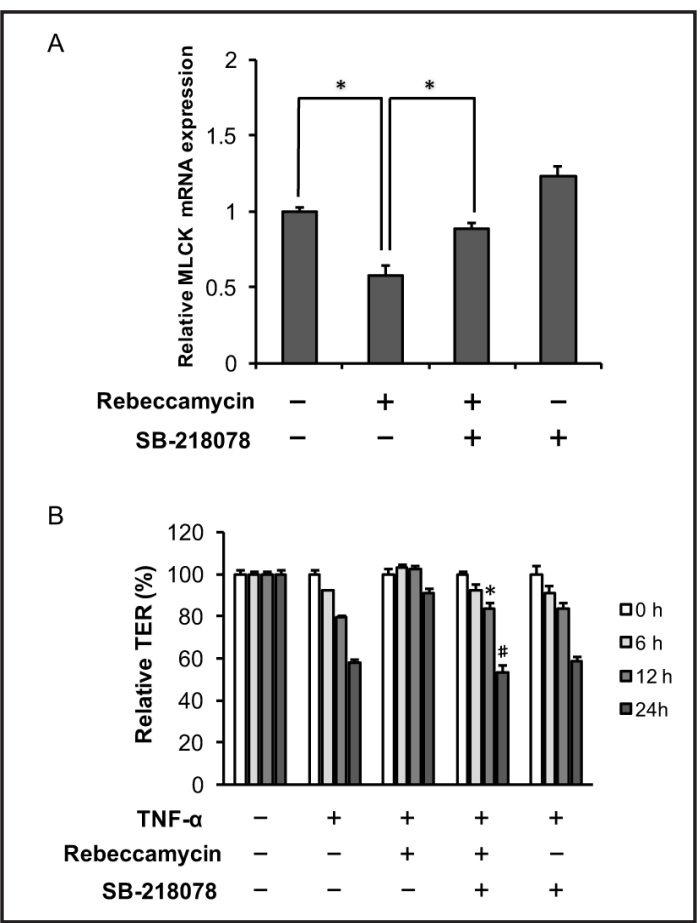

Fig. 6. Rebeccamycin-induced attenuation of TNF- $\alpha$-mediated barrier dysfunction is dependent on checkpoint kinase 1 activity. (A) Caco-2 cell monolayers were treated for $24 \mathrm{~h}$ with vehicle or rebeccamycin $(1 \mu \mathrm{M})$ in the absence or presence of the Chk1 inhibitor SB-218078 $(2 \mu \mathrm{M})$. Cell lysates were collected and subjected to qRT-PCR analysis for MLCK mRNA expression. ${ }^{*} P<0.05$, as determined by Tukey's test. (B) Caco-2 cell monolayers were treated with vehicle or TNF- $\alpha(10 \mathrm{ng} / \mathrm{mL})$ in the absence or presence of rebeccamycin $(1 \mu \mathrm{M})$ and/or SB$218078(2 \mu \mathrm{M})$. TER was measured at 6,12 , and 24 $h$. TER is presented as a percentage of the TER value at $0 \mathrm{~h}$. Data are presented as means $\pm \mathrm{SD}(\mathrm{n}=3) . P<$ 0.05 vs. TNF- $\alpha$ and rebeccamycin treatment for $12 \mathrm{~h}$ $\left(^{*}\right)$ or $24 \mathrm{~h}(\#)$, as determined by Tukey's test.

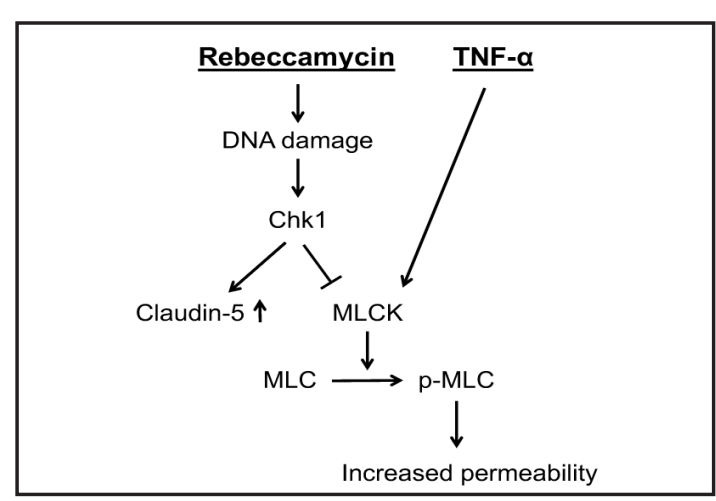

Fig. 7. Schematic illustration of the proposed protective action of rebeccamycin against intestinal epithelial barrier dysfunction triggered by TNF- $\alpha$. 
with the disruption of TJ assembly and impairment of intestinal epithelial barrier function $[37,38]$. MLC phosphorylation is induced by various kinases, including MLCK, ROCK, and PKC [39]. Several groups have reported that increased production and activation of MLCK by TNF- $\alpha$ modulate MLC phosphorylation in Caco-2 cells $[12,32]$. We showed here that rebeccamycin inhibited the increase in MLC phosphorylation in Caco-2 cells treated with TNF- $\alpha$ by reducing MLCK mRNA expression. Thus, inhibition of MLCK production may be one mechanism by which rebeccamycin attenuates the intestinal barrier dysfunction induced by TNF- $\alpha$. In addition, rebeccamycin increases claudin- 5 production, thus increasing the epithelial barrier integrity of Caco-2 cells [29], indicating that rebeccamycin can ameliorate the barrier dysfunction induced by TNF- $\alpha$ by modulating the production of MLCK and claudin-5 (Fig. 7).

Chk1 is a serine/threonine protein kinase that maintains genome integrity by regulating cell cycle checkpoints in response to DNA damage or incomplete DNA replication. Chk1 is regulated by ataxia-telangiectasia and RAD3-related protein under DNA damage, facilitating cell-cycle arrest and DNA repair [40,41]. Previously, we showed that Chk1 also plays a pivotal role in the enhancement of TJ barrier function that is induced by DNA damage in Caco- 2 cells [29]. We showed here that rebeccamycin inhibits MLCK production and alleviates TNF- $\alpha-$ induced barrier dysfunction via a mechanism that is partly dependent on the Chk1 pathway. These observations suggest that rebeccamycin-mediated Chk1 activation is essential for the protective action of rebeccamycin against TNF- $\alpha$-induced intestinal epithelial barrier dysfunction. Daunorubicin and cisplatin, which both induce DNA damage and activate Chk1, suppress NF-kB-dependent transcription [42]. TNF- $\alpha$-induced dysfunction of intestinal TJ barrier function involves NF-kB activation [22, 32]. The promoter region of the MLCK gene has NF-kB-binding sites, and this region is essential for the regulation of MLCK production $[43,44]$. Furthermore, NF-kB activation by proinflammatory cytokines increases MLCK production by Caco-2 cells $[22,25]$. These findings suggest that rebeccamycin-mediated inhibition of MLCK production is involved in NF-kB modulation. However, the mechanism of regulation of MLCK production by Chk1 activity requires further investigation.

A number of reports have revealed that proinflammatory cytokines disrupt intestinal epithelial barrier function. Whether the dysfunction of intestinal epithelial barrier function in inflammatory bowel disease is the cause or consequence of mucosal inflammation remains unclear. However, the development of strategies that address the damage to intestinal epithelial barrier function in IBD would be of value to overall therapeutic strategies for IBD $[11,45-48]$. We showed here that rebeccamycin inhibits the TNF- $\alpha$-induced upregulation of MLC phosphorylation mediated by MLCK via Chk1 activation; this might be the molecular mechanism of the protective action of rebeccamycin against the intestinal epithelial barrier dysfunction triggered by TNF- $\alpha$. Although further studies of rebeccamycin-induced enhancement of barrier function are needed, our findings suggest that an understanding of the molecular mechanism of regulation of MLCK and claudin- 5 production by Chk1 might provide new insights into strategies for treating IBD.

\section{Acknowledgements}

We thank Ms. Kaori Ikuma and Shizuka Yamagishi for their technical assistance. This work was supported by JSPS KAKENHI Grant No. 26860078 and 16K08370; by the Suzuken Memorial Foundation; by the Mishima Kaiun Memorial Foundation; by the Yokoyama Rinsho Yakuri Foundation; by the Platform for Drug Discovery, Informatics, and Structural Life Science of the Ministry of Education, Culture, Sports, Science, and Technology, Japan; and by the Basic Science and Platform Technology Program for innovative Biological Medicine from AMED.

\section{Disclosure Statement}

The authors declare that they have no conflicts of interest with the contents of this article. 


\section{Cellular Physiology Cell Physiol Biochem 2017;41:1924-1934 and Biochemistry Publisnedontme:Aprilo7, $2017 \quad \begin{aligned} & \text { DOI: 10.1159/000472367 } 2017 \text { The Author(s). Published by S. Karger AG, Basel } \\ & \text { www.karger.com/cpb }\end{aligned}$ \\ Watari et al.: Rebeccamycin Attenuates TNF- $\alpha$-Induced TJ Barrier Dysfunction}

\section{References}

1 Turner JR: Intestinal mucosal barrier function in health and disease. Nat Rev Immunol 2009;9:799-809.

2 Blikslager AT, Moeser AJ, Gookin JL, Jones SL, Odle J: Restoration of barrier function in injured intestinal mucosa. Physiol Rev 2007;87:545-564.

-3 Groschwitz KR, Hogan SP: Intestinal barrier function: molecular regulation and disease pathogenesis. J Allergy Clin Immunol 2009;124:3-20; quiz 21-22.

-4 Ferraris RP, Diamond J: Regulation of intestinal sugar transport. Physiol Rev 1997;77:257-302.

-5 Kunzelmann K, Mall M: Electrolyte transport in the mammalian colon: mechanisms and implications for disease. Physiol Rev 2002;82:245-289.

6 Broer S: Amino acid transport across mammalian intestinal and renal epithelia. Physiol Rev 2008;88:249286.

7 Odenwald MA, Turner JR: Intestinal permeability defects: is it time to treat? Clin Gastroenterol Hepatol 2013;11:1075-1083.

8 Farquhar MG, Palade GE: Junctional complexes in various epithelia. J Cell Biol 1963;17:375-412.

-9 Tsukita S, Furuse M, Itoh M: Multifunctional strands in tight junctions. Nat Rev Mol Cell Biol 2001;2:285293.

10 Van Itallie CM, Anderson JM: Claudins and epithelial paracellular transport. Annu Rev Physiol 2006;68:403429.

11 Hering NA, Fromm M, Schulzke JD: Determinants of colonic barrier function in inflammatory bowel disease and potential therapeutics. J Physiol 2012;590:1035-1044.

-12 Wang F, Graham WV, Wang Y, Witkowski ED, Schwarz BT, Turner JR: Interferon-gamma and tumor necrosis factor-alpha synergize to induce intestinal epithelial barrier dysfunction by up-regulating myosin light chain kinase expression. Am J Pathol 2005;166:409-419.

13 Al-Sadi R, Ye D, Dokladny K, Ma TY: Mechanism of IL-1beta-induced increase in intestinal epithelial tight junction permeability. J Immunol 2008;180:5653-5661.

14 Suzuki T, Yoshinaga N, Tanabe S: Interleukin-6 (IL-6) regulates claudin-2 expression and tight junction permeability in intestinal epithelium. J Biol Chem 2011;286:31263-31271.

-15 Weber CR, Raleigh DR, Su L, Shen L, Sullivan EA, Wang Y, Turner JR: Epithelial myosin light chain kinase activation induces mucosal interleukin-13 expression to alter tight junction ion selectivity. J Biol Chem 2010;285:12037-12046.

16 Sandborn WJ, Targan SR: Biologic therapy of inflammatory bowel disease. Gastroenterology 2002;122:1592-1608.

17 Braegger CP, Nicholls S, Murch SH, Stephens S, MacDonald TT: Tumour necrosis factor alpha in stool as a marker of intestinal inflammation. Lancet 1992;339:89-91.

18 Murch SH, Braegger CP, Walker-Smith JA, MacDonald TT: Location of tumour necrosis factor alpha by immunohistochemistry in chronic inflammatory bowel disease. Gut 1993;34:1705-1709.

19 van Deventer SJ: Anti-TNF antibody treatment of Crohn's disease. Ann Rheum Dis 1999;58:I114-120.

20 Ricart E, Panaccione R, Loftus EV, Tremaine WJ, Sandborn WJ: Infliximab for Crohn's disease in clinical practice at the Mayo Clinic: the first 100 patients. Am J Gastroenterol 2001;96:722-729.

21 Neurath MF, Fuss I, Pasparakis M, Alexopoulou L, Haralambous S, Meyer zum Buschenfelde KH, Strober W, Kollias G: Predominant pathogenic role of tumor necrosis factor in experimental colitis in mice. Eur J Immunol 1997;27:1743-1750.

22 Ma TY, Iwamoto GK, Hoa NT, Akotia V, Pedram A, Boivin MA, Said HM: TNF-alpha-induced increase in intestinal epithelial tight junction permeability requires NF-kappa B activation. Am J Physiol Gastrointest Liver Physiol 2004;286:G367-376.

23 Rodriguez P, Heyman M, Candalh C, Blaton MA, Bouchaud C: Tumour necrosis factor-alpha induces morphological and functional alterations of intestinal HT29 cl.19A cell monolayers. Cytokine 1995;7:441448.

-24 Cunningham KE, Turner JR: Myosin light chain kinase: pulling the strings of epithelial tight junction function. Ann N Y Acad Sci 2012;1258:34-42.

25 Ma TY, Boivin MA, Ye D, Pedram A, Said HM: Mechanism of TNF-\{alpha\} modulation of Caco-2 intestinal epithelial tight junction barrier: role of myosin light-chain kinase protein expression. Am J Physiol Gastrointest Liver Physiol 2005;288:G422-430. 


\section{Cellular Physiology Cell Physiol Biochem 2017;41:1924-1934 \begin{tabular}{l|l} 
DOI: 10.1159/000472367 & Ond Biochemistry \\
Published onlne: April07, 2017 & $\begin{array}{l}\text { 2017 The Author(s). Published by S. Karger AG, Basel } \\
\text { www.karger.com/cpb }\end{array}$
\end{tabular} \\ Watari et al.: Rebeccamycin Attenuates TNF- $\alpha$-Induced TJ Barrier Dysfunction}

26 Zolotarevsky Y, Hecht G, Koutsouris A, Gonzalez DE, Quan C, Tom J, Mrsny RJ, Turner JR: A membranepermeant peptide that inhibits MLC kinase restores barrier function in in vitro models of intestinal disease. Gastroenterology 2002;123:163-172.

27 Amasheh M, Fromm A, Krug SM, Amasheh S, Andres S, Zeitz M, Fromm M, Schulzke JD: TNFalpha-induced and berberine-antagonized tight junction barrier impairment via tyrosine kinase, Akt and NFkappaB signaling. J Cell Sci 2010;123:4145-4155.

-28 Facompre M, Baldeyrou B, Bailly C, Anizon F, Marminon C, Prudhomme M, Colson P, Houssier C: DNA targeting of two new antitumour rebeccamycin derivatives. Eur J Med Chem 2002;37:925-932.

29 Watari A, Hasegawa M, Yagi K, Kondoh M: Checkpoint Kinase 1 Activation Enhances Intestinal Epithelial Barrier Function via Regulation of Claudin-5 Expression. PLoS One 2016;11:e0145631.

30 Cao M, Wang P, Sun C, He W, Wang F: Amelioration of IFN-gamma and TNF-alpha-induced intestinal epithelial barrier dysfunction by berberine via suppression of MLCK-MLC phosphorylation signaling pathway. PLoS One 2013;8:e61944.

- 31 Chen SW, Zhu J, Zuo S, Zhang JL, Chen ZY, Chen GW, Wang X, Pan YS, Liu YC, Wang PY: Protective effect of hydrogen sulfide on TNF-alpha and IFN-gamma-induced injury of intestinal epithelial barrier function in Caco-2 monolayers. Inflamm Res 2015;64:789-797.

-32 He F, Peng J, Deng XL, Yang LF, Camara AD, Omran A, Wang GL, Wu LW, Zhang CL, Yin F: Mechanisms of tumor necrosis factor-alpha-induced leaks in intestine epithelial barrier. Cytokine 2012;59:264-272.

-33 Van Antwerp DJ, Martin SJ, Kafri T, Green DR, Verma IM: Suppression of TNF-alpha-induced apoptosis by NF-kappaB. Science 1996;274:787-789.

-34 Mankertz J, Amasheh M, Krug SM, Fromm A, Amasheh S, Hillenbrand B, Tavalali S, Fromm M, Schulzke JD: TNFalpha up-regulates claudin-2 expression in epithelial HT-29/B6 cells via phosphatidylinositol-3-kinase signaling. Cell Tissue Res 2009;336:67-77.

-35 Luettig J, Rosenthal R, Lee IM, Krug SM, Schulzke JD: The ginger component 6-shogaol prevents TNFalpha-induced barrier loss via inhibition of PI3K/Akt and NF-kappaB signaling. Mol Nutr Food Res 2016;60:2576-2586.

-36 Petrache I, Verin AD, Crow MT, Birukova A, Liu F, Garcia JG: Differential effect of MLC kinase in TNFalpha-induced endothelial cell apoptosis and barrier dysfunction. Am J Physiol Lung Cell Mol Physiol 2001;280:L1168-1178.

37 Turner JR, Rill BK, Carlson SL, Carnes D, Kerner R, Mrsny RJ, Madara JL: Physiological regulation of epithelial tight junctions is associated with myosin light-chain phosphorylation. Am J Physiol 1997;273:C1378-1385.

38 Clayburgh DR, Barrett TA, Tang Y, Meddings JB, Van Eldik LJ, Watterson DM, Clarke LL, Mrsny RJ, Turner JR: Epithelial myosin light chain kinase-dependent barrier dysfunction mediates $\mathrm{T}$ cell activation-induced diarrhea in vivo. J Clin Invest 2005;115:2702-2715.

-39 Tsukamoto 0, Kitakaze M: Biochemical and physiological regulation of cardiac myocyte contraction by cardiac-specific myosin light chain kinase. Circ J 2013;77:2218-2225.

- 40 Roos WP, Kaina B: DNA damage-induced cell death by apoptosis. Trends Mol Med 2006;12:440-450.

41 Zhang Y, Hunter T: Roles of Chk1 in cell biology and cancer therapy. Int J Cancer 2014;134:1013-1023.

42 Campbell KJ, Witty JM, Rocha S, Perkins ND: Cisplatin mimics ARF tumor suppressor regulation of RelA (p65) nuclear factor-kappaB transactivation. Cancer Res 2006;66:929-935.

43 Graham WV, Wang F, Clayburgh DR, Cheng JX, Yoon B, Wang Y, Lin A, Turner JR: Tumor necrosis factor-induced long myosin light chain kinase transcription is regulated by differentiation-dependent signaling events. Characterization of the human long myosin light chain kinase promoter. J Biol Chem 2006;281:26205-26215.

44 Ye D, Ma TY: Cellular and molecular mechanisms that mediate basal and tumour necrosis factor-alphainduced regulation of myosin light chain kinase gene activity. J Cell Mol Med 2008;12:1331-1346.

45 Hering NA, Schulzke JD: Therapeutic options to modulate barrier defects in inflammatory bowel disease. Dig Dis 2009;27:450-454.

-46 Watari A, Yagi K, Kondoh M: A simple reporter assay for screening claudin-4 modulators. Biochem Biophys Res Commun 2012;426:454-460.

47 Watari A, Hashegawa M, Muangman T, Yagi K, Kondoh M: Use of cell-based screening to identify smallmolecule compounds that modulate claudin-4 expression. Biotechnol Lett 2015;37:1177-1185.

-48 Han C, Ding Z, Shi H, Qian W, Hou X, Lin R: The Role of Probiotics in Lipopolysaccharide-Induced Autophagy in Intestinal Epithelial Cells. Cell Physiol Biochem 2016;38:2464-2478. 